\title{
The use of Cinnamon (Cinnamomum Bark) for Patients with Chronic Prostatitis/Chronic Pelvic Pain Syndrome: A Randomized Controlled Trial
}

\author{
Harth Mohamed Kamber ${ }^{1 *}$, Tawfiq Jasim Mohammed Al-Marzooq ${ }^{2}$, Malath Anwar Hussein ${ }^{1}$, Qays Ahmed Hassan², \\ Ahmed Abid Marzouq ${ }^{4}$ \\ ${ }^{1}$ Department of Surgery, Division of Urology, Al-Kindy College of Medicine, University of Baghdad, Baghdad, Iraq; ${ }^{2}$ Department \\ of Surgery, Al-Kindy College of Medicine, University of Baghdad, Baghdad, Iraq; ${ }^{3}$ Department of Surgery, Division of Radiology, \\ Al-Kindy College of Medicine, University of Baghdad, Baghdad, Iraq; ${ }^{4}$ Department of Community medicine, Al-Kindy College of \\ Medicine, University of Baghdad, Baghdad, Iraq
}

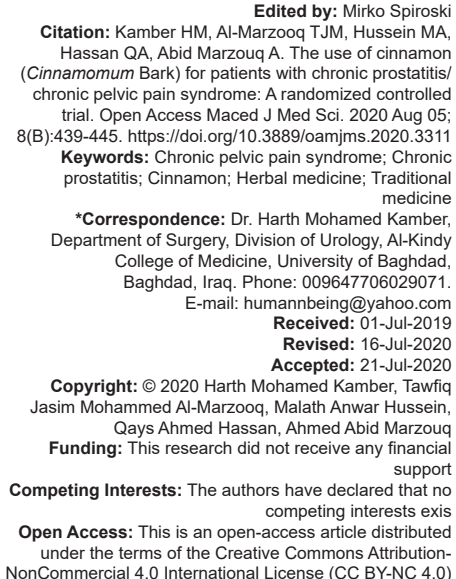

\section{Abstract}

BACKGROUND: Chronic prostatitis/chronic pelvic pain syndrome (CP/CPPS) is common, yet no curative treatment identified. Cinnamon is a herbal substance, which has many applications in medicine.

AIM: The aim of the study was to study the effect of cinnamon on patients with chronic pelvic pain syndrome.

METHODS: Sixty patients with documented CP/CPPS randomized into two groups during 2018 and 2019 in Baghdad. The first group received 60 capsules each contained $1 \mathrm{~g}$ of cinnamon. The other group received 60 capsules each contained $1 \mathrm{~g}$ of sugar powder (placebo). All the patients instructed to take one capsule twice daily for 1 month. National Institutes of Health-Chronic Prostatitis Symptom Index (NIH-CPSI) was reported for both groups at baseline and after 1 month of treatment. The primary outcome was a patient perceivable improvement defined as a reduction of the NIH-CPSI by 6 or more points after 1 month, whereas improvement of sub-scores of NIH-CPS (pain, urinary symptoms, and quality of life) considered as a secondary outcome, and adverse reactions reported.

RESULTS: Thirteen patients (43.3\%) of the cinnamon group have 6 or more points of reduction in the total NIH-CPS compared to four patients $(13.3 \%)$ of the control groups $(p=0.01)$. The improvement in total NIH-CPSI score was mainly due to improvement in pain sub-score, whereas in urinary symptoms, there was marginal change with no significant change in the quality of life score. The only reported side effect was gastric upset in one patient.

CONCLUSION: The study concluded that cinnamon improves NIH-CPSI in patients with CP/CPPS.

\section{Introduction}

National Institutes of Health $(\mathrm{NIH})$ defines chronic prostatitis/chronic pelvic pain syndrome (CP/ CPPS) as the presence of genitourinary pain in the absence of uropathogenic bacteria detected by standard microbiologic methodology [1], [2], [3]

The presence of symptoms resembling that of CP/CPPS in different population fall in the range between $2.2 \%$ and $9.7 \%$ with a mean prevalence of $8.2 \%$, making CP/CPPS as one of common urologic problems. Nevertheless, its etiology and pathophysiology are poorly understood with no solid guidelines for effective treatment [4], [5].

Prolonged period of antibiotic therapy is usually used as the first line in the treatment of CP/CPPS in the first place regardless of the finding of prostatic fluid microscopic examination and culture. When this approach fails, the next option of managements which have been tried and investigated include medications such as alpha-blockers, anti-inflammatory drugs, muscle relaxants, anticonvulsants, phosphodiesterase type 5 inhibitors or even hormonal manipulation, also physiotherapy, behavioral therapy, herbal, or even surgical interventions. Despite the multiplicity of the treatment options, none of these options proved curative for all patients with CP/CPPS. Therefore, the trial of different treatment options in the hope of finding effective treatment is justifiable [6], [7].

Cinnamon is the bark of trees belonging to the genus Cinnamomum. It is an aromatic spice that is used in traditional medicine for multiple purposes, including relieving of pain. Cinnamon is also proved to have an antibacterial effect (Figure 1) [8], [9], [10].

Cinnamon has a well-known scent due to its oil content, which has a high concentration of cinnamaldehyde in addition to several other compounds 
such as cinnamyl acetate, L-borneol, caryophyllene oxide, eugenol, b-caryophyllene, L-bornyl acetate, E-nerolidol, a-terpineol, a-cubebene, terpinolene, and $\alpha$-thujene. Besides, cinnamon contains a variety of resinous compounds, including cinnamate and cinnamic acid [11, [12], [13].

Cinnamon has been long used in kitchens as spice and appetizer without reported serious adverse events. The beneficial health attributes of cinnamon and its derivative and components reported by several researchers. These include its antimicrobial, antiinflammatory, antioxidant, anti-diabetic, analgesic, and even anticancer properties. Nevertheless, further studies are still required to illuminate the potential health benefits of the spice [14], [15], [16], [17], [18]

The "National Institutes of Health Chronic Prostatitis Symptom Index" (NIH-CPSI) is developed as a tool to assess the severity of symptoms of $\mathrm{CP} /$ CPPS [19].

A reduction of 6 or more points in the $\mathrm{NIH}-\mathrm{CPSI}$ score showed to be clinically perceivable difference by the patients in the previous studies [20].

A validated Arabic version of $\mathrm{NIH}-\mathrm{CPSI}$ showed "excellent internal consistency" and correlates well with the severity of symptoms in patients with $\mathrm{CP} /$ CPPS [21].

This study is designed to observe the effect of cinnamon on patients with chronic pelvic pain syndrome.

\section{Materials and Methods}

\section{Ethical approval and registration}

The study approved by the Scientific Unit and Medical Ethics Committee at Al Kindy College of Medicine, University of Baghdad and had the approval number: 165.10/04/2019.

The study registered on ClinicalTrials.gov with the ID: NCT03946163.

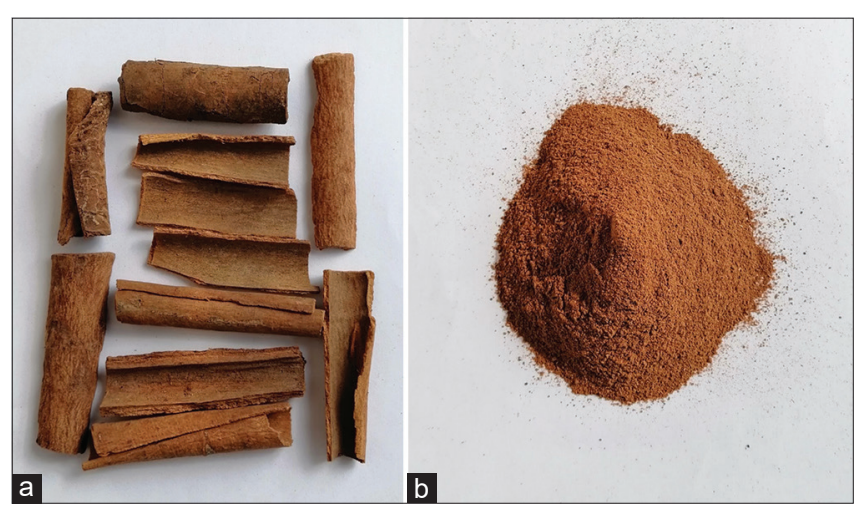

Figure 1: Cinnamon barks (a) and powder (b)

\section{Sample size}

For pilot trials sample size estimation, the rules of thumb can be simply applied, Browne RH states a general role: "Use at least 30 subjects or greater to estimate a parameter," whereas Julious SA proposes 12 subjects per intervention arm to be the minimal acceptable sample size. This study intended for a sample size of 30 patients on each arm of the study [22], [23].

\section{Patients inclusion}

This placebo-controlled clinical trial included 60 patients diagnosed with CP/CPPS with a minimum duration of symptoms of 6 months. All recruited from the urology outpatient clinic in Al-Kindy Teaching Hospital in Baghdad in the period from February 1, 2018 , to June 30,2019 . From all of the patients, clinical history was taken and proper physical examination was performed. Relevant investigations obtained including ultrasonography of abdomen and pelvis, urinalysis, and culture and sensitivity for initial, midstream, and postprostatic massage urine sample (or expressed prostatic secretions when available), serum prostate-specific antigen, and investigations for sexually transmitted diseases performed when relevant.

Patients with food allergies, previous transurethral intervention, positive urine culture or positive prostatic secretions culture, uncontrolled medical diseases (such as diabetes, hypertension, or asthma), or patients using analgesics for other conditions (such as musculoskeletal pain) were excluded from the study sample.

All the patients received before inclusion in the study at least 3 months coarse of oral antibiotics, some of them were treated with alpha-blockers, anticholinergic drugs or both, others tried nonsteroidal anti-inflammatory drugs, all of the patients had partial or no improvement to previous treatments, none of them have complete resolution of the condition. At the time of inclusion, the patients were off any other treatment for their condition for at least 1 month. patients.

Written informed consent signed by all of the

Any patient aged more than 18 years was eligible for the study as far as he can approve his participation in the study; there was no upper limit for the ages of the participants

\section{Study protocol}

The patients were randomized into two groups by flipping a coin for each new odd-numbered participant to assign him to one of the two groups; the next participant was automatically assigned to the other group. Each patient in the first groups received 60 capsules, each capsule contained $1 \mathrm{~g}$ of cinnamon bark 
powder and instructed to take one capsule twice daily for 1 month. Whereas each patient in the other group received 60 capsules similar to those given to the first group in shape, size, color, and smell containing $1 \mathrm{~g}$ of sugar powder as a placebo and instructed to take one capsule twice daily for 1 month. The compliance of the patients with the treatment was measured by counting the residual capsule after conclusion of the study period.

Each patient filled a written validated questionnaire of translated $\mathrm{NIH}-\mathrm{CPSI}$ (Arabic version) before starting treatment and 1 month later. Each patient on the questionnaire can score a total of (0-43) (the higher the score, the more severe are the symptoms). The total score divided into three sub-scores for the following domains: Pain (0-21), urinary symptoms (0-10), and quality of life (0-12) [21].

Any complaints of the patients from the drug or unwanted effects were reported as adverse effects.

The study was triple blinded; the patients, the researchers, and the statistical investigator all were blinded to the content of the capsules until the conclusion of the study.

\section{Outcome measures}

A reduction in the $\mathrm{NIH}-\mathrm{CPSI}$ score of six or more points from the initial score (a patient perceivable improvement) considered as a positive response (the primary outcome). A reduction in the total $\mathrm{NIH}-\mathrm{CPSI}$ or in one or more of its sub-scores dealt with as a minor positive response (secondary outcome). The adverse effects were reported.

\section{Statistical analysis}

The data were analyzed using SPSS version 16 using descriptive statistics for all variables, independent t-test to compare both groups before the intervention, covariance analysis to analyze continuous variables regarding the effect of the intervention on both groups, and Chi-square test to analyze categorical variable regarding the effect of the intervention on both groups. $p<0.05$ was considered significant.

\section{Results}

Of the 64 patients recruited for the clinical trial, four patients were excluded: One due to food allergy, two patients were excluded one due to uncontrolled chronic obstructive airway disease and the other due to uncontrolled diabetes mellitus, another patient decline to participate in the clinical trial. The remaining 60 patients randomized into two groups, 30 patients in each group (Figure 2).
Table 1: Patients' age and duration of complaint of studied subjects according to the group of study

\begin{tabular}{llllll}
\hline Group & Group & $\mathrm{n}$ & Mean & SD & p-value \\
\hline Age (years) & Control & 30 & 37.2 & 11.04 & 0.927 \\
& Cinnamon & 30 & 37.0 & 8.51 & \\
& Total & 60 & & & \\
Duration (months) & Control & 30 & 13.3 & 8.18 & 0.674 \\
& Cinnamon & 30 & 12.6 & 4.77 & \\
& Total & 60 & & & \\
\hline *Statistical tests used an independent t-test. Significant p<0.05. & & &
\end{tabular}

There was no significant difference between the two groups regarding the age, duration of symptoms (Table 1), total NIH-CPSI score, and individual $\mathrm{NIH}-$ CPSI sub-scores (Table 2).

Table 2: Pain, urinary symptoms, quality of life, and NIH-CPSI scores of studied subjects before intervention according to the group of study

\begin{tabular}{llllll}
\hline Group & Group & $\mathrm{n}$ & Mean & $\mathrm{SD}$ & $\mathrm{p}$ value \\
\hline Pain & Control & 30 & 11.1 & 4.55 & $0.704^{*}$ \\
\multirow{2}{*}{ Urinary symptoms } & Cinnamon & 30 & 10.6 & 4.90 & \\
& Control & 30 & 5.8 & 3.15 & $0.141^{*}$ \\
\multirow{2}{*}{ Quality of life } & Cinnamon & 30 & 4.7 & 2.71 & \\
& Control & 30 & 6.7 & 3.29 & $0.354^{*}$ \\
\multirow{2}{*}{ NIH-CPSI } & Cinnamon & 30 & 6.0 & 2.63 & \\
& Control & 30 & 23.7 & 8.69 & $0.273^{*}$ \\
& Cinnamon & 30 & 21.3 & 7.61 & \\
\hline "Statistical tests used a two sample t-test. Significant p<0.05. NIH-CPSI: National Institutes of Health-
\end{tabular}

*Statistical tests used a two sample t-test. Significant $p<0.05$. NIH-CPSI: National Institutes of HealthChronic Prostatitis Symptom Index.

In the cinnamon group, $13(43.3 \%)$ subjects had six or more points of reduction (patient perceivable improvement) in the total $\mathrm{NIH}-\mathrm{CPSI}$ compared to 4 $(13.3 \%)$ subjects in the control group, making the primary response in the cinnamon group more significant than that of the control group with $p=0.01$. The overall reduction in $\mathrm{NIH}-\mathrm{CPSI}$ score was significantly observed in the cinnamon group compared to the control group (Table 3).

Table 3: Association between cinnamon treatment and primary response

\begin{tabular}{|c|c|c|c|c|c|c|c|}
\hline \multirow[t]{2}{*}{ Group } & \multicolumn{2}{|c|}{ Yes } & \multicolumn{2}{|l|}{ No } & \multirow[t]{2}{*}{ p value ${ }^{*}$} & \multirow{2}{*}{$\begin{array}{l}\text { Odds } \\
\text { ratio }\end{array}$} & \multirow{2}{*}{$\begin{array}{l}95 \% \text { Confidence } \\
\text { interval }\end{array}$} \\
\hline & $\mathrm{n}$ & Percentage & n & percentage & & & \\
\hline Cinnamon & 13 & 43.3 & 17 & 56.7 & 0.010 & 4.4971 & $1.387,17.816$ \\
\hline Control & 4 & 13.3 & 26 & 86.7 & & & \\
\hline
\end{tabular}

On the level of individual domain score, there was significant reduction in the pain score in the cinnamon groups compared to the control group. On the other hand, decrement of urinary symptoms in the control group with increment in the cinnamon group made a significant difference between the two groups (Table 4).

The quality of life score was improved (decreased) for both groups, but more prominent in the cinnamon group, yet the difference was not statistically significant (Table 4).

One subject from the cinnamon group reported gastric upset (acidity) and treated by antacid. No other side effect was reported in both groups.

\section{Discussion}

Cinnamon produced perceivable improvement in patients with CP/CPPS by reducing mainly the pain 


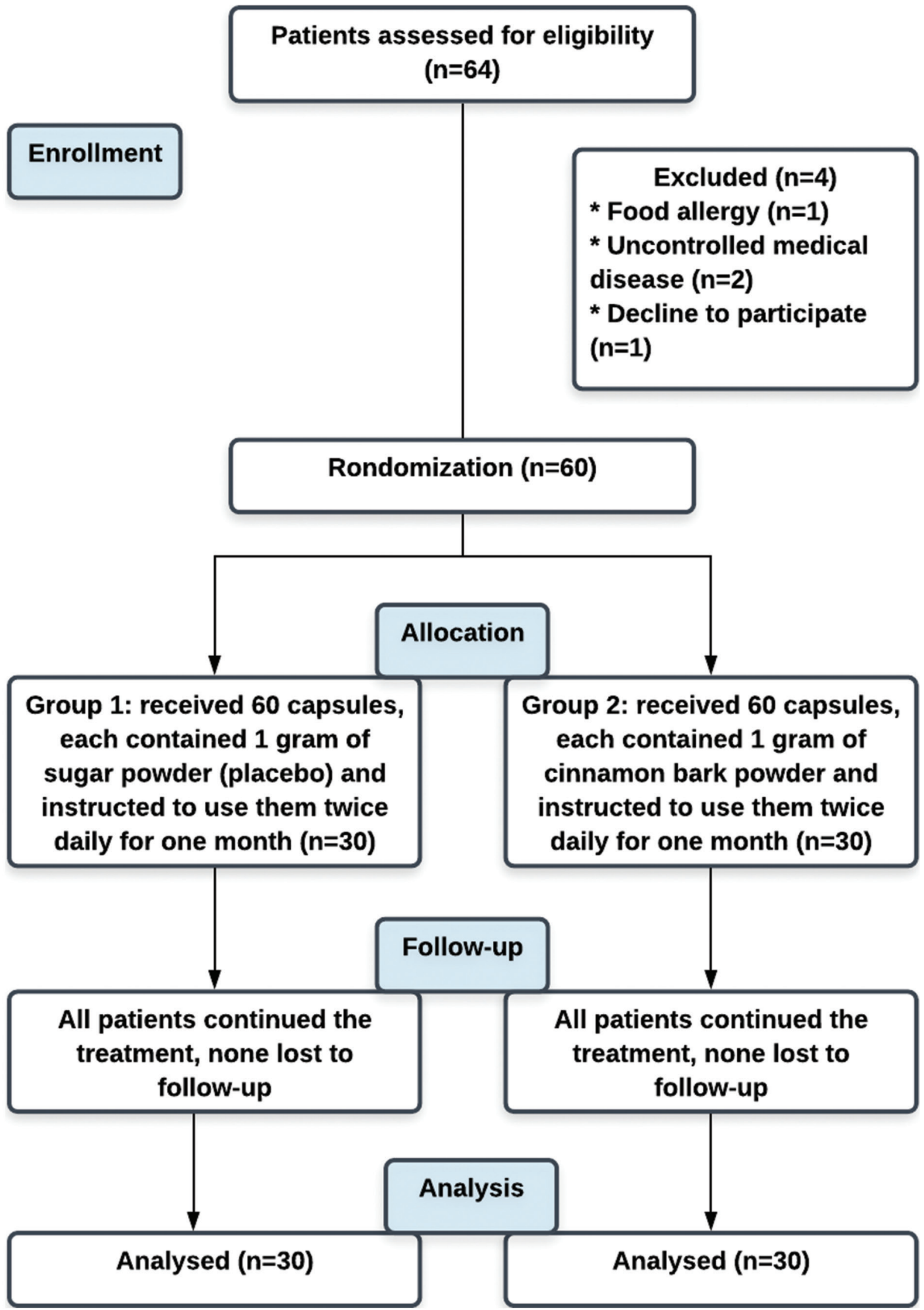

Figure 2: CONSORT flowchart of the research plan 
Table 4: The effect of cinnamon treatment in comparison with placebo on total NIH-CPSI score, pain score, urinary symptoms score, and quality of life score

\begin{tabular}{|c|c|c|c|c|c|c|c|c|c|}
\hline \multirow[t]{2}{*}{ Score } & \multirow[t]{2}{*}{ Group } & \multirow[t]{2}{*}{$\mathrm{n}$} & \multirow{2}{*}{$\begin{array}{l}\text { Estimated baseline } \\
\text { mean }\end{array}$} & \multicolumn{2}{|c|}{ Estimated end line } & \multirow{2}{*}{$\begin{array}{l}95 \% \text { Confidence } \\
\text { interval }\end{array}$} & \multirow{2}{*}{$\begin{array}{l}\text { Outcome } \\
\text { (Endline-baseline) }\end{array}$} & \multirow{2}{*}{$\begin{array}{l}\% \text { of } \\
\text { difference }\end{array}$} & \multirow[t]{2}{*}{$p$ value } \\
\hline & & & & Mean & SE & & & & \\
\hline \multirow[t]{2}{*}{$\mathrm{NIH}-\mathrm{CPSI}$} & Control & 30 & 22.53 & 19.99 & 0.616 & $18.765,21.230$ & -2.54 & -12.71 & $0.007^{\star}$ \\
\hline & Cinnamon & 30 & & 17.53 & 0.616 & $16.303,18.768$ & -5.00 & -28.52 & \\
\hline \multirow[t]{2}{*}{ Pain } & Control & 30 & 10.87 & 9.395 & 0.382 & $8.63,10.159$ & -1.48 & -15.70 & $0.001^{*}$ \\
\hline & Cinnamon & 30 & & 6.305 & 0.382 & $5.541,7.070$ & -4.57 & -72.40 & \\
\hline \multirow{2}{*}{ Urinary symptoms } & Control & 30 & 5.27 & 4.87 & 0.223 & $4.421,5.315$ & -0.40 & -8.21 & $0.005^{*}$ \\
\hline & Cinnamon & 30 & & 5.80 & 0.223 & $5.789,6.245$ & 0.53 & 9.14 & \\
\hline \multirow[t]{2}{*}{ Quality of life score } & Control & 30 & 6.40 & 5.80 & 0.224 & $5.349,6.247$ & -0.60 & -10.34 & $0.183^{*}$ \\
\hline & Cinnamon & 30 & & 5.37 & 0.224 & $4.920,5.818$ & -1.03 & -19.18 & \\
\hline
\end{tabular}

The proposed etiology of CP/CPPS includes infection, inflammation, hormonal, and neuronal reasons or even autoimmunity may contribute to the development of CP/CPPS [24].

Proper management of CP/CPPS has always been a challenging task due to elusive etiological mechanisms [25].

Effect of cinnamon on pain was reported for perineal and pelvic pain in the previous studies and found to produce a noticeable improvement in primary dysmenorrhea and after episiotomy [17], [18], [26], [27].

Cinnamon essential oil possesses antinociceptive properties. Its potency in chronic pain inhibition was similar to diclofenac, though its acute antinociceptive effect reported to be less than morphine in mice [28].

Cinnamon extract in high doses decreased the chronic pain intensity in animal studies [28], [29].

The pain-reducing action found in this study is consistent with that found in other studies. Jaafarpour et al. in 2015 and Jahangirifar et al. in 2018 both found that cinnamon significantly reduces the pain of primary dysmenorrhea. Mohammadi et al. in 2014 found that the local use of cinnamon ointment improves healing and reduces the pain of episiotomy incisions [17], [18], [26], [27].

Dashti-Rahmatabadi et al. in 2009 found that cinnamon extract in high dose decreases the intensity of chronic formalin-induced pain in rats [29].

Cinnamon has documented anti-inflammatory effect probably through anti-complement activity and inhibition of complement-dependent inflammatory cascade [30], [31].

Antioxidant activity of cinnamon extracts, its essential oil, and eugenol (one of its components) documented in vitro using an oxidative $\beta$-carotene/ linoleic acid system, peroxynitrite-induced nitration, lipid peroxidation, and 1,1-diphenyl-2-picrylhydrazine test [32], [33], [34], [35], [36].

Thermo-sensitive transient receptor potential (TRP) channels, especially TRPV1 and TRPA1, are activated by the pungent compounds present in spices. Studies showed that TRPA1 agonists such cinnamaldehyde, the pungent ingredients in cinnamon activate the sensory nerves and induce adrenaline secretion through the central nervous system [37].
Furthermore, linalool is one of the monoterpene compounds in cinnamon that affects pain receptors and causes analgesia. Linalool creates inhibitory capability in the central nervous system neurons by opening potassium channels. Phenols like eugenol inhibit calcium entrance inside the cell and so control the release of neurotransmitters interfering in pain from terminals of afferent fibers in the posterior horn of the spinal cord [29], [38].

The pain-relieving properties of cinnamon can be the result of its anti-inflammatory, antioxidant, TRPA1-activation-induced central adrenaline secretion, linalool central nervous system inhibitory properties, eugenol pain transfer inhibitory properties, or the combination of some, or all of the above [29], [32], [33], [34], [35], [36], [37], [38].

The minor increment in urinary symptoms sub-score is probable due to the pungent effect of cinnamaldehyde; the aromatic compound of cinnamon.

Spicy food found to aggravate symptoms in CP/CPPS by Herati et al., although the paper they published did not demonstrate the change in specific domains in NIH-CPSI [39].

Tripp et al. in 2004 reported that the quality of life in patients with CP/CPPS correlated directly with both pain and urinary symptoms, with pain being the most "robust predictor" for the quality of life in these patients [40].

The quality of life improved more for the cinnamon group, but not to the point of statistical significance. This can be explained by the improvement of pain accompanied by worsening of urinary symptoms.

The side effect of cinnamon reported in this study is expected since self-limiting gastrointestinal adverse events are the most commonly reported side effect of cinnamon [41].

The study limited by the relatively short period of follow-up, a longer period of follow-up to observe the consistency of the change in symptoms would provide a more reliable outcome. Another limitation is the number of the recruited patients; although based on reliable literature, a larger number of patients would provide more power to the study. Another limitation of this study is the use of the translated version of the NIH-CPSI, the validation of the translated version does not make the perception of the patient to the questionnaire as that of the native English speaker to the English version, but 
it gives acceptable reliability to the results of the score obtained from it.

\section{Conclusion}

Cinnamon produces patient-perceivable improvement in symptoms of patients with CP/CPPS. For these patients, cinnamon reduces the total $\mathrm{NIH}$ CPSI significantly through reduction of pain, yet it probably affects the urinary symptoms adversely and does not affect the quality of life significantly, whereas the side effects are minor and tolerable.

We recommend further studies on a larger group of patients with CP/CPPS to confirm the beneficial effect of cinnamon with the early exclusion of those who have worsening of their urologic symptoms. Besides, cinnamon contains multiple active ingredients, the study of separate, isolated chemicals extracted from cinnamon may prove better improvement with less adverse effects, further isolation, and study of each ingredient alone is a noteworthy recommendation.

\section{Acknowledgments}

The authors would like to thank Al-Kindy Teaching Hospital for their co-operation in achieving this research and to thank Dr. Yousif Abdul Rahim professor of community medicine in Al-Kindy College of Medicine for his invaluable support and advice.

\section{References}

1. Magistro G, Nickel J. Evaluation of chronic prostatitis/chronic pelvic pain syndrome. 2019;10:295-301.

PMid:19570491

2. Krieger JN, Nyberg L Jr., Nickel JC. NIH consensus definition and classification of prostatitis. JAMA. 1999;282(3):236-7. https://doi.org/10.1001/jama.282.3.236

PMid:10422990

3. DeWitt-Foy ME, Nickel JC, Shoskes DA. Management of chronic prostatitis/chronic pelvic pain syndrome. Eur Urol Focus. 2019;5(1):2-4. https://doi.org/10.1016/j.euf.2018.08.027 PMid:30206001

4. Krieger JN, Lee SW, Jeon J, Cheah PY, Liong ML, Riley DE. Epidemiology of prostatitis. Int J Antimicrob Agents. 2008;31(Suppl 1):85-90. https://doi.org/10.1016/j. ijantimicag.2007.08.028 PMid: 18164907

5. NickelJC.Prostatitis:Mythsandrealities. Urology. 1998;51(3):3626. https://doi.org/10.1016/s0090-4295(97)00643-2

\section{PMid:9510337}

6. Lee SW. Recent trend of chronic prostatitis/chronic pelvic pain syndrome (CP/CPPS) management. Hanyang Med Rev. 2017;37(1):40-6. https://doi.org/10.7599/hmr.2017.37.1.40

7. Hasan HF. The use of tadalafilin patients with chronic prostatitis/ chronic pelvic pain syndrome. Iraqi J Med Sci. 2013;11(1):78-83.

8. Hempen $\mathrm{CH}$, Fischer T. A MATERIA Medica for Chinese Medicine: Plants, Minerals, and Animal Products. Amsterdam, Netherlands: Elsevier Health Sciences; 2009.

9. Nabavi S, Di Lorenzo A, Izadi M, Sobarzo-Sánchez E, Daglia M. Antibacterial effects of cinnamon: From farm to food, cosmetic and pharmaceutical industries. Nutrients. 2015;7(9):7729-48. https://doi.org/10.3390/nu7095359

PMid:26378575

10. Chen P, Sun J, Ford P. Differentiation of the four major species of cinnamons (C. burmannii, C. verum, C. cassia, and C. loureiroi) using a flow injection mass spectrometric (FIMS) fingerprinting method. J Agric Food Chem. 2014;62(12):2516-21. https://doi. org/10.1021/jf405580c

PMid:24628250

11. Senanayake UM, Lee TH, Wills RB. Volatile constituents of cinnamon (Cinnamomum zeylanicum) oils. J Agric Food Chem. 1978;26(4):822-4. https://doi.org/10.1021/jf60218a031

12. Tung YT, Chua MT, Wang SY, Chang ST. Anti-inflammation activities of essential oil and its constituents from indigenous cinnamon (Cinnamomum osmophloeum) twigs. Bioresour Technol. 2008;99(9):3908-13. https://doi.org/10.1016/j. biortech.2007.07.050

PMid: 17826984

13. Tung YT, Yen PL, Lin CY, Chang ST. Anti-inflammatory activities of essential oils and their constituents from different provenances of indigenous cinnamon (Cinnamomum osmophloeum) leaves. Pharm Biol. 2010;48(10):1130-6. https:// doi.org/10.3109/13880200903527728

PMid:20815702

14. Rao PV, Gan SH. Cinnamon: A multifaceted medicinal plant. Evid Based Complement Altern Med. 2014;2014:642942. https://doi.org/10.1155/2014/642942 PMid:24817901

15. Al-Ani RA, Adhab MA, Nawar HH. Antibacterial activity of clove, cinnamon, and datura extracts against Erwinia carotovora subsp. atroseptica causative agent of black stem and soft rot on potato. J Med Plants Res. 2012;6(10):1891-5.

16. Al-dhaher ZA. The antibacterial activity of aqueous extract of cinnamon and clove against Staphylococcus aureus. Al-Nahrain J Sci. 2008;11(2):131-5. https://doi.org/10.22401/jnus.11.2.19

17. Jaafarpour M, Hatefi M, Khani A, Khajavikhan J. Comparative effect of cinnamon and Ibuprofen for treatment of primary dysmenorrhea: A randomized double-blind clinical trial. J Clin Diagn Res. 2015;9(4):QC04. https://doi.org/10.7860/ jcdr/2015/12084.5783

PMid:26023601

18. Mohammadi A, Mohammad-Alizadeh-Charandabi $S$ Mirghafourvand $M$, Javadzadeh $Y$, Fardiazar $Z$, EffatiDaryani $F$. Effects of cinnamon on perineal pain and healing of episiotomy: A randomized placebo-controlled trial. J Integr Med. 2014;12(4):359-66. https://doi.org/10.1016/ s2095-4964(14)60025-x

PMid:25074885

19. Litwin MS, McNaughton-Collins M, Fowler FJ, Nickel JC, Calhoun EA, Pontari MA, et al. The National Institutes of Health chronic prostatitis symptom index: Development and validation of a new outcome measure. J Urol. 1999;162(2):369-75. https:// doi.org/10.1016/s0022-5347(05)68562-x

PMid:10411041 
20. Propert KJ, Litwin M, Wang $\mathrm{Y}$, Alexander RB, Calhoun E, Nickel JC, et al. Responsiveness of the national institutes of health chronic prostatitis symptom index (NIH-CPSI). Qual Life Res. 2006;15(2):299-305. https://doi.org/10.1007/ s11136-005-1317-1

\section{PMid:16468084}

21. El-Nashaar A, Fathy A, Zeedan A, Al-Ahwany A, Shamloul R Validity and reliability of the arabic version of the national institutes of health chronic prostatitis symptom index. Urol Int. 2006;77(3):227-31. https://doi.org/10.1159/000094814 PMid: 17033210

22. Browne RH. On the use of a pilot sample for sample size determination. Stat Med. 1995;14(17):1933-40. PMid:8532986

23. Julious SA. Sample size of 12 per group rule of thumb for a pilot study. Pharm Stat. 2005;4(4):287-91.

24. Pontari MA, Ruggieri MR. Mechanisms in prostatitis/chronic pelvic pain syndrome. J Urol. 2008;179(5):S61-7. https://doi. org/10.1016/j.juro.2008.03.139

PMid:18405756

25. Kouiavskaia DV, Southwood S, Berard CA, Klyushnenkova EN Alexander RB. T-cell recognition of prostatic peptides in men with chronic prostatitis/chronic pelvic pain syndrome. J Urol. 2009;182(5):2483-9. https://doi.org/10.1016/j.juro.2009.07.067 PMid:19765754

26. Jahangirifar M, Taebi M, Dolatian M. The effect of Cinnamon on primary dysmenorrhea: A randomized, double-blind clinical trial. Complementary therapies in clinical practice. 2018;33:56-60. https://doi.org/10.1016/j.ctcp.2018.08.001 PMid:30396627

27. Jaafarpour M, Hatefi M, Najafi $F$, Khajavikhan J, Khani $A$. The effect of cinnamon on menstrual bleeding and systemic symptoms with primary dysmenorrhea. Iran Red Crescent Med J. 2015;17(4):e27032. https://doi.org/10.5812/ircmj.17(4)2015.27032 PMid:26023350

28. Dashti RM, Qane MD, Shefaie F, Nazemian Yazdu M, Bagheri SM. Comparative effect of cinnamon essential oil, diclofenac and morphine on acute and chronic pain in mice. Int J Med Lab. 2016;3(2):92-103.

29. Dashti-Rahmatabadi M, Merjardi AV, Pilavaran A, Farzan F. Antinociceptive effect of cinnamon extract on formalin induced pain in rat. SSU J. 2009;17(2):190-9.

30. Nagai $H$, Shimazawa $T$, Matsuura $N$, Koda $A$. Immunopharmacological studies of the aqueous extract of Cinnamomum cassia (CCAq) I. anti-allergic action. Jpn J Pharmacol. 1982;32(5):813-22. https://doi.org/10.1254/ jjp.32.813 PMid:7176217

31. Shen Y, Jia LN, Honma N, Hosono T, Ariga T, Seki T. Beneficial effects of cinnamon on the metabolic syndrome, inflammation, and pain, and mechanisms underlying these effects a review. J Tradit Complement Med. 2012;2(1):27-32. https://doi. org/10.1016/s2225-4110(16)30067-0

\section{PMid:24716111}

32. Shobana S, Naidu KA. Antioxidant activity of selected Indian spices. Prostaglandins Leukot Essent Fatty Acids. 2000;62(2):107-10. https://doi.org/10.1054/plef.1999.0128 PMid: 10780875

33. Dragland S, Senoo H, Wake K, Holte K, Blomhoff R. Several culinary and medicinal herbs are important sources of dietary antioxidants. J Nutr. 2003;133(5):1286-90. https://doi. org/10.1093/jn/133.5.1286

PMid:12730411

34. Chericoni S, Prieto JM, lacopini P, Cioni P, Morelli I. In vitro activity of the essential oil of Cinnamomum zeylanicum and eugenol in peroxynitrite-induced oxidative processes. J Agric Food Chem. 2005;53(12):4762-5.

PMid: 15941312

35. Mancini-Filho J, Van-Koiij A, Mancini D, Cozzolino F, Torres R. Antioxidant activity of cinnamon (Cinnamomum zeylanicum, Breyne) extracts. Boll Chim Farm. 1998;137(11):443-7. PMid:10077878

36. Okawa M, Kinjo J, Nohara T, Ono M. DPPH (1, 1-diphenyl-2picrylhydrazyl) radical scavenging activity of flavonoids obtained from some medicinal plants. Biol Pharm Bull. 2001;24(10):12025. https://doi.org/10.1248/bpb.24.1202 PMid:11642334.

37. Iwasaki $\mathrm{Y}$, Tanabe M, Kobata $\mathrm{K}$, Watanabe T. TRPA1 agonists allyl isothiocyanate and cinnamaldehyde induce adrenaline secretion. Biosci Biotechnol Biochem. 2008;72(10):2608-14. https://doi.org/10.1271/bbb.80289

PMid:18838811.

38. Bahmani M, Shirzad H, Majlesi M, Shahinfard $N$, Rafieian-Kopaei M. A review study on analgesic applications of Iranian medicinal plants. Asian Pac J Trop Med. 2014;7:S43S53. https://doi.org/10.1016/s1995-7645(14)60202-9 PMid:25312163.

39. Herati AS, Shorter B, Srinivasan AK, Tai J, Seideman C, Lesser $\mathrm{M}$, et al. Effects of foods and beverages on the symptoms of chronic prostatitis/chronic pelvic pain syndrome. Urology. 2013;82(6):1376-80. https://doi.org/10.1016/j. urology.2013.07.015 PMid:23978369.

40. Tripp DA, Nickel JC, Landis JR, Wang YL, Knauss JS, Group CS. Predictors of quality of life and pain in chronic prostatitis/chronic pelvic pain syndrome: Findings from the national institutes of health chronic prostatitis cohort study. BJU Int. 2004;94(9):127982. https://doi.org/10.1111/j.1464-410x.2004.05157.x PMid:15610105.

41. Hajimonfarednejad M, Ostovar M, Raee MJ, Hashempur MH, Mayer JG, Heydari M. Cinnamon: A systematic review of adverse events. Clin Nutr. 2019;38(2):594-602. https://doi. org/10.1016/j.clnu.2018.03.013

PMid:29661513. 